\title{
Twitter as a Platform for an Israeli Community of Information Science Professionals
}

\author{
Ina Blau, Department of Education \& Psychology, and \\ Tami Neuthal, Shoham Center, \\ The Open University of Israel, Ra'anana, Israel
}

\author{
inabl@openu.ac.il, tamine@openu.ac.il
}

\begin{abstract}
This paper examines an Israeli professional community on Twitter, which connects people working or studying the field of Information Science. The participants were 31 individual and organizational users and 175 structural connections established among them during March 2007- November 2011. The data was extracted using NodeXL application and analyzed in terms of user's investments (i.e., participation by tweeting and following others) and gratification mechanisms (i.e., influence on the audience: the degree of centrality into the community network, the number of followers and tweets marked as favorites). The results show that (1) The evolution of the community over time was in a bell curve, in concordance with the Diffusion of Innovations Theory (Rogers, 2003). (2) Concerning the rate of active participation, five of the most active individual community members $(16.1 \%)$ shared $54 \%$ of the community tweets. Thus, the head of this "long tail" distribution is relatively small, indicating a moderate level of participation inequality in the community. (3) Regarding user investment and gratification mechanisms, participation by tweeting and following others is highly related to the visible form of influencing community audience the number of followers, moderately related to the hidden influence - location of the participant in the community network measured by PageRank, and unrelated to the content quality - the percentage of user's tweets marked as favorites by others.
\end{abstract}

Keywords: professional communities of practice on Twitter, structural connections on Twitter, influence on the audience, active participation, network analysis by NodeXL.

\section{Introduction}

Professional communities of practice have moved recently from online forums to social networks platforms. Social media have triggered much interest in communities of practice because these platforms are well aligned with the peer-to-peer learning processes typical of communities of practice (Wenger, 2010). Twitter is a social network and microblogging service enabling people

Material published as part of this publication, either on-line or in print, is copyrighted by the Informing Science Institute. Permission to make digital or paper copy of part or all of these works for personal or classroom use is granted without fee provided that the copies are not made or distributed for profit or commercial advantage AND that copies 1) bear this notice in full and 2) give the full citation on the first page. It is permissible to abstract these works as long as credit is given. To copy in all other cases or to republish or to post on a server or to redistribute to lists requires specific permission and payment of a fee. Contact Publisher@InformingScience.org to request redistribution permission. to share with others short textual messages up to 140 characters - tweets (Boyd, Golder, \& Lotan, 2010), as well as links to resources, images or video clips. Twitter was ranked in the top three services used by Semantic Web researchers in order to spread information (Letierce, Passant, Decker, \& Breslin, 2010). 
This paper uses network analysis to investigate an Israeli professional community of people working or studying the field of Library and Information Science and using Twitter to connect with similar others. The Literature review section first discusses the use of Twitter by professional communities of practice. Following that, this sub-section explores two complementary ways of addressing change of platform by these communities: Diffusion of Innovation Theory, which looks at the technology adoption over time, and the rate of active participation / content contribution using the Pareto Law. To conclude, the review discusses relationships between user investment and gratification mechanisms based on the Uses and Gratification framework.

\section{Literature Review}

A professional community of practice is as a social learning system in which learning becomes an informal and dynamic social structure among the participants (Wenger, 2010). Arising out of learning, professional communities of practice exhibit many characteristics of systems such as complex relationships, self-organization, emergent structure, dynamic boundaries, and ongoing negotiation of professional competency and cultural meaning. Professionals use Twitter to stay informed on current trends relevant to their practices and to simultaneously communicate with other team members (Zhao \& Rosson, 2009) or colleagues, and to acquire conference and publish updates (Reinhardt et al., 2009). Therefore, the role of Twitter in professional settings is more as a platform for real-time content sharing than for social networking (Chang, 2010).

Changing a platform for online activity by members of the professional community of practice can be addressed in two complementary ways. One way is to explore the adoption of the new platform over time. Similarly to other technological innovations, Twitter is accepted at different rates, according to individual differences between the community members. Highly innovative people are known as active information seekers (Coursaris, Yum, \& Sung, 2010). Rogers (2003) defined innovativeness as "the degree to which an individual or other unit of adoption is relatively earlier in adopting an innovation than other members of a social system" (p. 22). The Diffusion of Innovation Theory of Rogers describes five types of technology adopters over time. The distribution of these types follows standard deviations in a bell curve: from innovators (2.5\%) and early adopters (13.5\%), through early (34\%) and late majority (34\%), to laggards (16\%). Diffusion of Innovation Theory offers valuable insights regarding the adoption of an innovation by modeling its entire life cycle (Chang, 2010).

A different way of looking at participation is by measuring a level of participation or content contribution relatively to other community members at a one time-point. The majority of Internet users in general, and participants of social network communities in particular, are consumers, while only a small fraction of the participants function as content contributors (Forkosh-Baruch \& Hershkovitz, 2012). Applying the Pareto Law to users' online behavior (Persky, 1992), this distribution ranges near the $20: 80$ rule, according to which $20 \%$ of the participants produce $80 \%$ of the value. This "long tail" distribution of online participation is neither restricted to the medium nor to the participant's age (Blau, 2011). Because Twitter is a network of interconnected actors rather than constraining conversation within bounded spaces or groups, the participants may have a sense of being surrounded by a conversation, without being active content contributors (Boyd et al., 2010). The stream of messages spread through this platform allows community members to be peripherally aware and consume information without active participation. Therefore the motivation for active participation on Twitter is beyond the need to be informed.

Uses and Gratification framework (Rubin \& Bantz, 1987) focuses on motives for technology usage - how social and psychological needs drive usage of different media to satisfy users' needs and expected outcomes from media-related behaviors. Connections between Twitter users are directed: participants can follow others and see their tweets, but the other users need not reciprocate (Boyd et al., 2010). Similarly to participation in other social network platforms (Blau, Zuck- 
erman, \& Monroy-Hernández, 2009; Zuckerman, Blau, \& Monroy-Hernández, 2009), these directed structural connections enable us to investigate the behavior of Twitter users in terms of Uses and Gratification framework, examining user investment- active and passive participation by tweeting and following others, and gratification mechanisms - different forms of influencing the audience (Blau \& Neuthal, 2012).

\section{Study Hypotheses}

This paper examines an Israeli professional community on Twitter that connects users working or studying the field of Library and Information Science. We hypothesized that:

(1) The evolution of the community would be consistent with the Diffusion of Innovations Model (Rogers, 2003)

(2) Consistent with the Pareto Law, the level of active participation by tweeting would be approximately according to the 20:80 rule

(3) Consistent with Uses and Gratification framework (Rubin \& Bantz, 1987) and empirical findings regarding participation in other social network platforms (Blau et al., 2009; Zuckerman et al., 2009) and participation in other communities of practice on Twitter (Blau \& Neuthal, 2012), the level of participant investment onto the community (i.e., participation by tweeting and following others) would correlate with gratification mechanisms (i.e., influence on the audience).

\section{Method}

\section{Participants}

The participants were 31 individual and organizational Israeli Twitter accounts of users working or studying the field of Library and Information Science and 175 structural connections (edges) among them - open and continuous following of one user by another - established until November 2011. Twitter default and norm is keeping the profiles public (Boyd et al., 2010), but users can make their tweets public or protected (i.e., private). We verified the absence of private accounts among the participants in order to be able to present their usernames in community evolution figures; only public tweets were extracted and analyzed.

The accounts were collected by appropriate search queries in Hebrew and English, checking followers of professional organizations and academic institutions in the field, and confirming the activity level of the accounts (Forkosh-Baruch \& Hershkovitz, 2011, 2012). Consistent with the claim investigating communication in general and Twitter connections in particular by focusing on active participants (Cha et al., 2010), all Twitter accounts included in the analysis were active, i.e., showed at least a minimum level of activity during six months before collecting the data.

\section{Instruments and Procedure}

The data was exported and analyzed using NodeXL - an open source social media network analysis add-in (Smith et al., 2009). The evolution of the community over time was presented using dynamic filters of NodeXL. Edges representing structural connections are time-stamped. Thus, dynamic filters allow exploration of a structural network over time, while fixing the location of the nodes, i.e., the users (Hansen, Smith, \& Shneiderman, 2011).

The activities of the community members were analyzed in terms of user investments (i.e., participation measured by tweeting and following others) and gratification mechanisms (i.e., influence on the audience measured by the degree of centrality into the community network measured by PageRank (Blau \& Neuthal, 2012; Weng, Lim, Jiang, \& He, 2010), number of followers - an indicator of a user's popularity (Cha et al., 2010), and the number and percentage of tweets 
marked as favorites by others (i.e., numbers of favorite tweets by total number of tweets) that can indicate the quality of content contribution. Table 1 presents descriptive statistics of these measures.

Table 1: Descriptive statistics of participation and influence on the audience measures

\begin{tabular}{lccccc}
\hline & \multicolumn{2}{c}{ Participation } & \multicolumn{3}{c}{ Influence } \\
& Tweets & Followed & PageRank & Followers & Favorites \\
\hline Mean & 375.81 & 134.55 & 0.99 & 173.32 & 2.65 \\
Median & 207 & 51 & 0.95 & 64 & 0 \\
Standard Deviation & 441.57 & 176.93 & 0.58 & 274.48 & 5.16 \\
Skewness & 1.42 & 2.18 & 1.03 & 2.33 & 3.00 \\
Minimum & 6 & 1 & 0.25 & 9 & 0 \\
Maximum & 1523 & 782 & 2.46 & 1069 & 24 \\
\hline
\end{tabular}

As can be seen from the data presented, all the measures of participation and influence on the audience show the "long tail" distribution. In absence of normal distribution, Spearman rank correlation coefficient was used in the Results section in order to explore relationships between different forms of participation and influence on the audience.

\section{Results and Discussion}

This section first presents the evolution of the community over time, following by the exploration of active participation rate. To conclude, the relationships between participation forms and influence on the audience are analyzed.

\section{Evolution of the Community Over Time}

The analysis of the community shows four sub-groups (presented by different geometrical forms in the figures below) having unequal representation. The members have numerous connections within and between the groups. The exploration of the community evolution over time revealed that first members joined Twitter on 13 March, 2007 and only two of four sub-groups formed the community during the first and the second years (Figures 1 and 2). 

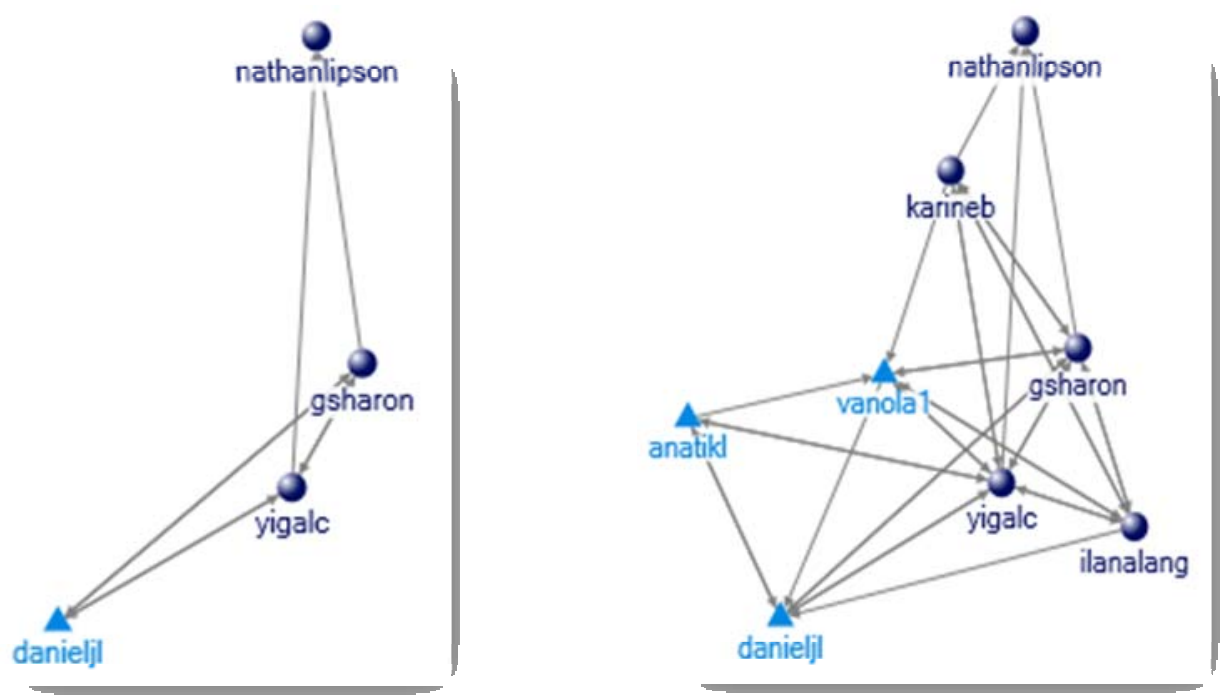

Figure 1: The end of the $1^{\text {st }}$ year (March 2008) Figure 2: The end of the $2^{\text {nd }}$ year (March 2009)

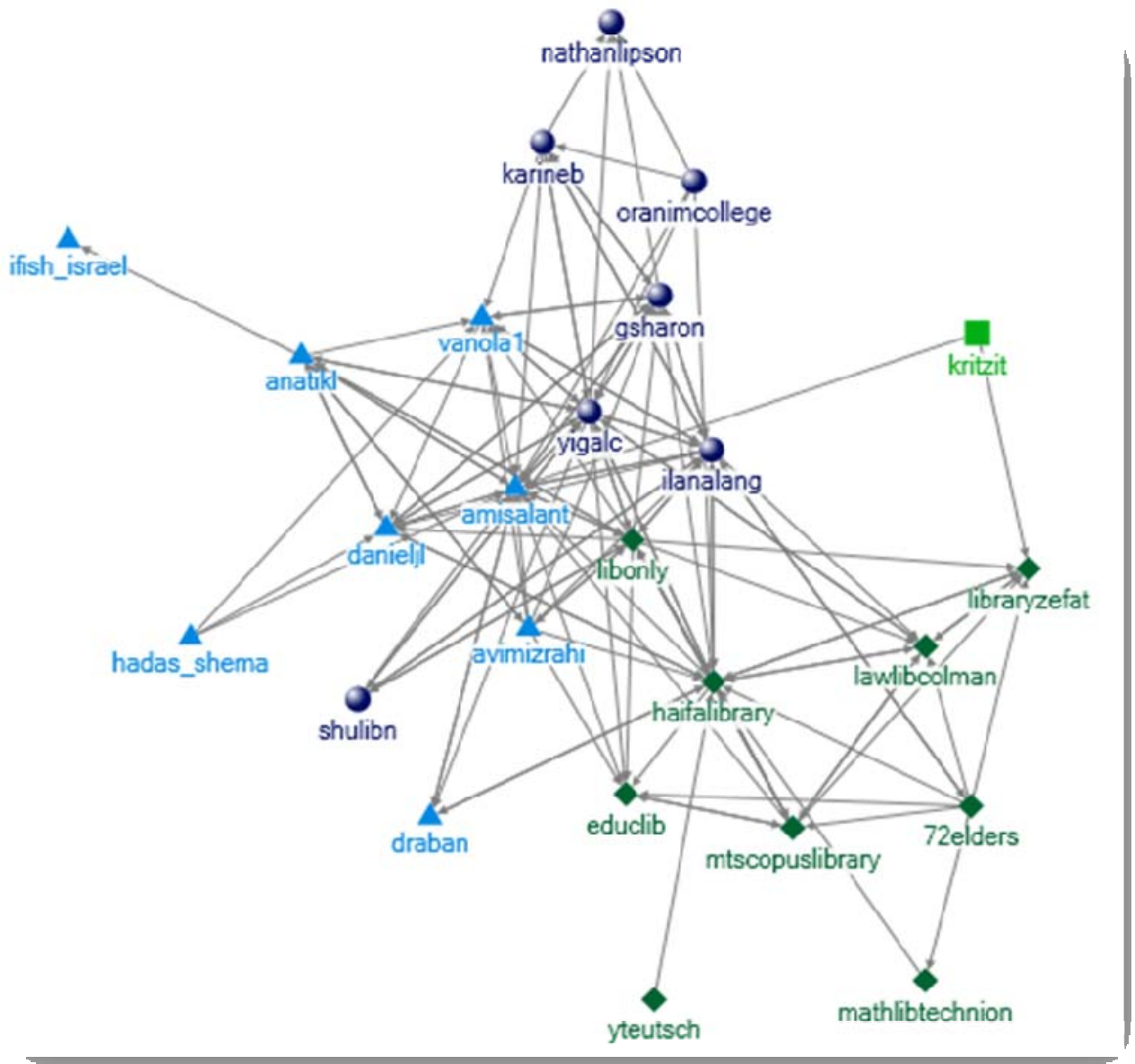

Figure 3: The community in the end of the $3^{\text {rd }}$ year (March 2010) 
During the third year (Figure 3) the community expanded almost to its actual size, including participants from all sub-groups and organizational users. Since then and until the data extraction in November 2011 (a year and eight months) only few users joined the community and few new structural connections were established among the existing members (Figure 4).

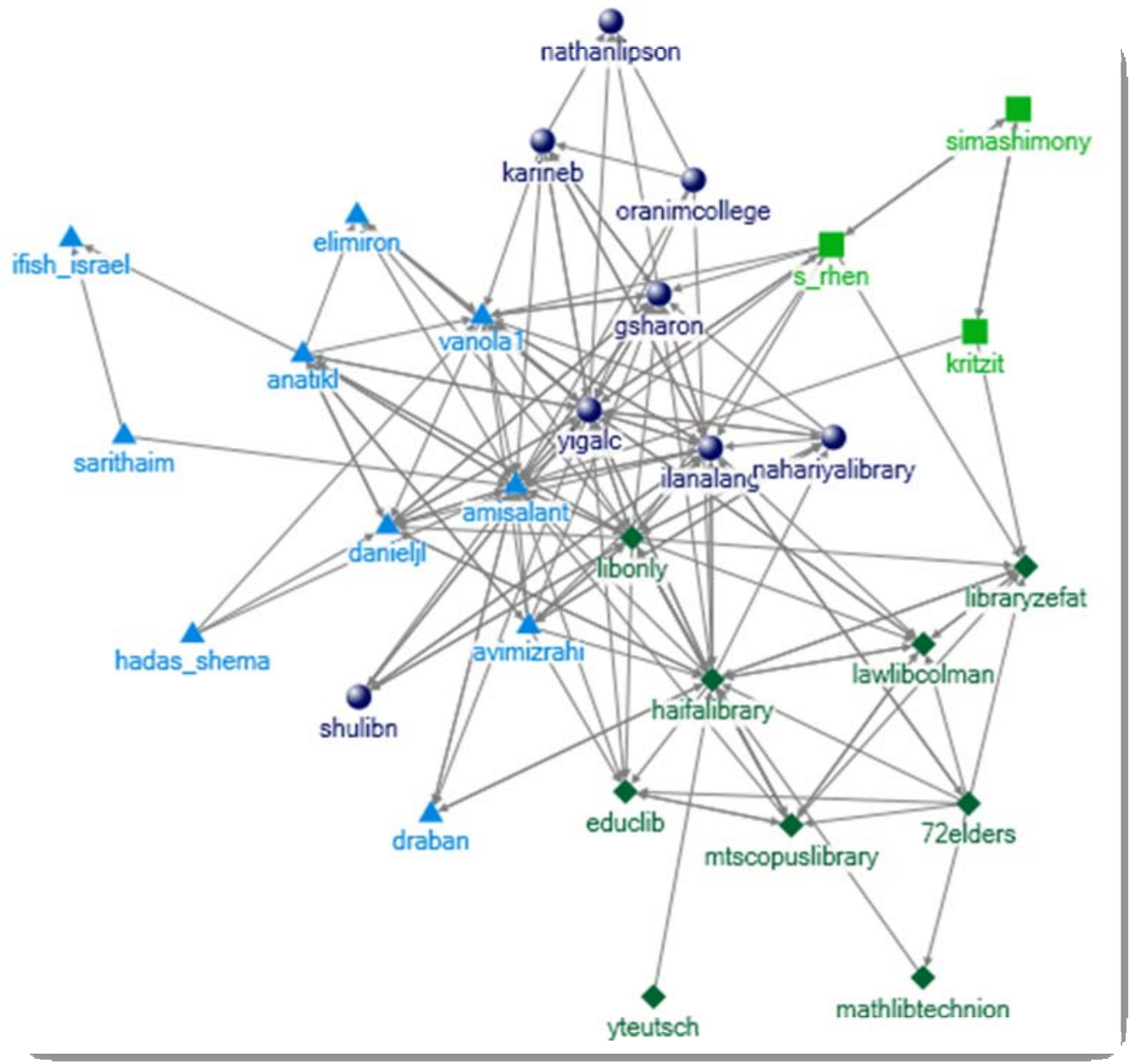

Figure 4: The community in November 2011 (the last year and 8 months)

As can be seen from the figures above, the evolution of this professional Twitter community is consistent with the Diffusion of Innovation Model (Rogers, 2003). Similar to normal distribution curve, only few participants and few connections among them established during the first two years as well as during the last year and eight months of the investigation. Most of the participants joined the community and started to follow one another during the third year of its existence. Rogers has suggested that one of the motives for adopting innovation is the perceived popularity of this innovation. In other words, technology adoption may be caused not only by actual needs of an individual user, but also by social norms and pressure. Since the participants of this study were a relatively small professional community of people working or studying the field of Library and Information Science, once a social norm of professional connections via Twitter was established, social pressure pushed the early and the late majority to adopt the platform dur- 
ing the third year of investigation and the dispersion of the adoption distribution was small. These patterns of adoption are similar to those of another relatively small Israeli professional community practicing Educational Technologies on Twitter (Blau \& Neuthal, 2012). Diffusion of Innovation Theory offers valuable insight modeling an entire life cycle of the innovation adoption (Chang, 2010). It seems that moving existing small professional communities of practice on Twitter takes about five years and at the time of writing this paper we are approaching the end of this process.

\section{Active Participation Rate}

During four years and eight months of the community's existence, its 31 members shared 11,650 tweets. About $54 \%$ of the tweets were shared by five most active individual community members (16.1\%). Despite the "long tail" distribution of tweets, the head of this distribution is relatively smaller than described by the 20:80 rule, indicating a moderate level of participation inequality in the community. This finding differs from the result of investigation in Israeli professional community practicing Educational Technologies on Twitter (Blau \& Neuthal, 2012) where inequality was significantly higher. It seems that professionals working or studying the field of Library and Information Science show more willingness for the active dissemination of information.

\section{Participation and Influence on the Audience}

Table 2 shows Spearman rank correlations between the participation modes of tweeting and following others and influence on the audience measured by PageRank, number of followers, number and percentage of tweets marked as favorites by others.

Table 2: Correlation between the participation and influencing the audience measures

\begin{tabular}{lcccc}
\hline & PageRank & Followers & N. of Favorites & $\%$ of Favorites \\
\hline Tweets & $.32^{* *}$ & $.77^{* * *}$ & $.22^{*}$ & -.03 \\
Followed & $.32^{* *}$ & $.63^{* * *}$ & .06 & -.10 \\
\hline${ }_{* * *} p<.001,{ }^{* *} p<.01,{ }^{*} p<.05$ &
\end{tabular}

As can be seen from the data presented, relationships between participation and influence on the audience differ according to the mode of measuring the influence. Tweeting and following others are highly correlated with number of followers. These results are similar to a previous study exploring Twitter use by Israeli academic institutions (Forkosh-Baruch \& Hershkovitz, 2012). It seems difficult to neutralize social relationships between participation and the visible form of influencing audience by following community members ("I follow people who follow me"). However, only medium correlations were found between the level of participation and the influence measured by PageRank invisible to others. This result is consistent with the investigation of an Israeli professional community practicing Educational Technologies on Twitter (Blau \& Neuthal, 2012). It seems that the degree of a user's centrality into the community network is not a part of the process of social pleasing. Statistically insignificant negative correlations were found between the participation and the percentage of tweets marked as favorites by other users, indicating that the quantity of users' participation and the quality of their content contribution as perceived by others are at least unrelated, if not reversed. 


\section{Conclusions}

This study investigated the adoption of Twitter by an Israeli professional community of practice, which connects people related to the field of Library and Information Science. The frameworks of this study were Diffusion of Innovation Theory (Rogers, 2003), looking at individual differences in adapting innovations over time, and Uses and Gratification approach, exploring the relationships between user investment by participation / content contribution and gratification mechanisms. (1) Consistent with the first research hypothesis, the evolution of the community over time was close to the normal distribution in a bell curve, in concordance with the Diffusion of Innovations Model (Rogers, 2003). The short period of massive adoption of the platform by early and late majority during the third year of investigation suggests that technology adaptation was stimulated by social norm rapidly disseminated in this small professional community. (2) Concerning the rate of active participation, the results show a moderate level of participation inequality in this community. Five of the most active community members (16.1\%) produce $54 \%$ of the community tweets. Thus, the head of this "long tail" distribution is smaller than described by the 20:80 rule, suggesting that professionals in the field of Information Science highly value the process of dissemination of information and therefore show more readiness for active content contribution. (3) Regarding the relationships between participation forms and influence on the audience, tweeting and following others are highly related to the visible and therefore "social" form of influence measured by the number of followers. However, only moderate relationships were found between the participation and the invisible form of influencing - the degree of the participant's centrality into the community network measured by PageRank, suggesting that this form of influence on the audience is free from pleasing other community members. Interestingly, the quantity of participation was not related to the quality of tweets marked as favorites by others. It seems that the number of followers serves as a main gratification mechanism directly experienced by community members.

This study contributes to the field by exploring the whole cycle of an existing professional community of practice after moving to a new platform and by presenting empirical support to the description of the Diffusion of Innovation Model (Rogers, 2003). In addition, the study shows differences in investment-gratification mechanisms of a community on Twitter. It seems that relationships between participation and influence on the audience differ according to the operationalization of the influence: visible to others (i.e. "social"), invisible, or based on the quality of content contribution. These results suggest that studying influence on the audience in social media, researchers should use different operationalizations of this concept. In addition, statistically insignificant negative correlations between the quantity and the quality of content contribution found in this study would make an interesting topic to explore in future research on professional communities of practice. The implications of our findings to communities of practice moving to a new platform is the importance of establishing a social norm of using this platform for professional interactions among members, which can significantly speed the process of new technology adoption. Following others was found in this study to be an important mechanism of gratification and can be used to enhance users' involvement and participation in communities of practice.

The main limitation of this study is the exclusive use of the data from Twitter service. Future studies should add the participants' voices in order to gain a deeper understanding of the rate of active participation as well as the relationships between participation and influence on the audience in professional communities on Twitter. 


\section{References}

Blau, I. (2011). E-collaboration within, between, and without institutions: Towards better functioning of online groups through networks. International Journal of e-Collaboration, 7, 22-36.

Blau, I., \& Neuthal, T. (2012, February). Social networking behavior in Israeli community practicing learning and information technologies on Twitter. Paper presented at the International Symposium on Cyber Behavior - CB2012. Taipei, Taiwan.

Blau, I., Zuckerman, O., \& Monroy-Hernández, A. (2009). Children participation in media content creation community: Israelis learners in Scratch programming environment. In Y. Eshet-Alkalai, A. Caspi, S. Eden, N. Geri, \& Y. Yair (Eds.), Learning in the Technological Era (pp.65-72). Ra'anana, Israel: Open University of Israel.

Boyd, D., Golder, S., \& Lotan, G. (2010). Tweet, tweet, retweet: Conversational aspects of retweeting on twitter. Paper presented at the HICSS -43. IEEE Computer Society. Kauai, HI. Retrieved February 19, 2012 from http://www.computer.org/portal/web/csdl/doi/10.1109/HICSS.2010.412

Cha, M., Haddadi, H., Benevenuto, F., \& Gummadi, K. P. (2010). Measuring user influence in twitter: The million follower fallacy. 4th International AAAI Conference on Weblogs and Social Media (ICWSM). Retrieved February 19, 2012 from http://www.aaai.org/ocs/index.php/ICWSM/ICWSM10/paper/download/1538/1826

Chang, H.-C. (2010). A new perspective on Twitter hashtag use: Diffusion of innovation theory. Proceedings of the American Society for Information Science and Technology - ASIST2010 (Vol. 47, pp. 1-4). Pittsburgh, PA: Wiley Online Library.

Coursaris, C. K., Yun, Y., \& Sung, J. (2010). Twitter users vs. quitters: A uses and gratification and diffusion of innovations approach in understanding the role of mobility in microblogging. Proceedings of the $9^{\text {th }}$ International Conference on Mobile Business $/ 9^{\text {th }}$ Global Mobility Roundtable - ICMB'2010GMR'2010 (pp.482-486).Athens, Greece.

Forkosh-Baruch, A., \& Hershkovitz, A. (2011). The use of social networks by higher-education institutes in Israel. In Y. Eshet-Alkalai, A. Caspi, S. Eden, N. Geri, \& Y. Yair (Eds.), Learning in the digital era (pp. 14-20). Ra'anana, Israel: Open University of Israel.

Forkosh-Baruch, A., \& Hershkovitz, A. (2012). A case study of Israeli higher-education institutes sharing scholarly information with the community via social networks. The Internet and Higher Education, 15, 58-68.

Hansen, D., Smith, M., \& Shneiderman, B. (2011). EventGraphs: Charting collections of conference connections. 44th Hawaii International Conference on System Sciences - HICSS (pp. 1-10). IEEE. Retrieved February 19, 2012 from http://ieeexplore.ieee.org/xpls/abs_all.jsp?arnumber=5718714

Letierce, J., Passant, A., Breslin, J., \& Decker, S. (2010). Understanding how Twitter is used to spread scientific messages. Paper presented at the Web Science Conference. Raleigh, NC, USA. Retrieved February 19, 2012 from http://journal.webscience.org/314/

Persky, J. (1992). Retrospectives: Pareto's law. Journal of Economic Perspectives, 6, 181-192.

Reinhardt et al. (2009). How people are using Twitter during conferences. In V. Hornung-Prähauser, \& M. Luckmann (Eds.) Proceeding of $5^{\text {th }}$ EduMedia conference Creativity and innovation competencies on the Web (pp. 145-156). Salzburg.

Rogers, E. M. (2003). Diffusion of innovations (5th ed.). New York: Free Press.

Rubin, A. M., \& Bantz, C. R. (1987). Utility of videocassette recorders. American Behavioral Scientist, 30(5), 471-485

Smith, M., B. Shneiderman, N. Milic-Frayling, E.M. Rodrigues, V. Barash, C. Dunne, T. Capone, A. Perer, \& E. Gleave (2009). Analyzing (social media) networks with NodeXL. Paper presented at C\&T'09 Conference. New York: ACM. Retrieved February 19, 2012 from http://www.smrfoundation.org/wp- 
content/uploads/2009/06/2009-ct-nodexl-and-social-queries-a-social-media-network-analysistoolkit1.pdf

Weng, J., Lim, E.-P., Jiang, J., \& He, Q. (2010). TwitterRank: Finding topic-sensitive influential Twitterers. Paper presented at the WSDM'10. NY, USA: ACM. Retrieved February 19, 2012 from http://ink.library.smu.edu.sg/cgi/viewcontent.cgi?article=1503\&context=sis_research

Wenger, E. (2010). Communities of practice and social learning systems: The career of a concept. In C. Blackmore (Ed.), Social learning systems and communities of practice (pp. 179-198). The Open University, London: Springer-Verlag.

Zhao, D., \& Rosson, M. B. (2009). How and why people Twitter: The role that micro-blogging plays in informal communication at work. Proceedings of the ACM 2009 international conference on supporting group work (pp. 243-252). Sanibel Island, Florida, USA.

Zuckerman, O., Blau, I., \& Monroy-Hernández, A. (2009). Children's participation patterns in online communities: An analysis of Israeli learners in the Scratch online community. Interdisciplinary Journal of E-Learning and Learning Objects, 5, 263-274.

\section{Biographies}

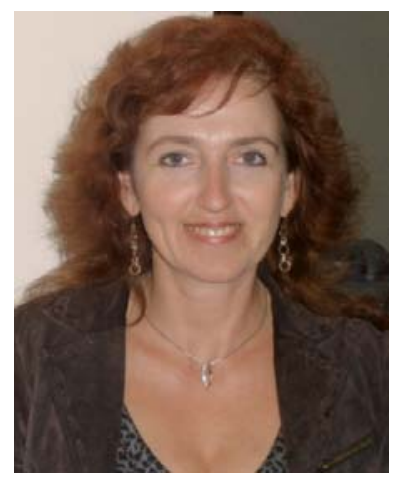

Dr. Ina Blau holds a PhD in E-Learning and CyberPsychology from the University of Haifa, Israel. She is a senior faculty in the Department of Education and Psychology at the Open University of Israel. In addition, she teaches in the Department of Information and Knowledge Management, Graduate School of Management, University of Haifa. Her research interests include social aspects of Internet use and ecommunication, online risks and safety, participation patterns, ecollaboration, as well as integration of innovative technologies in education system and organizations.

http://www.openu.ac.il/Personal_sites/ina-blau/

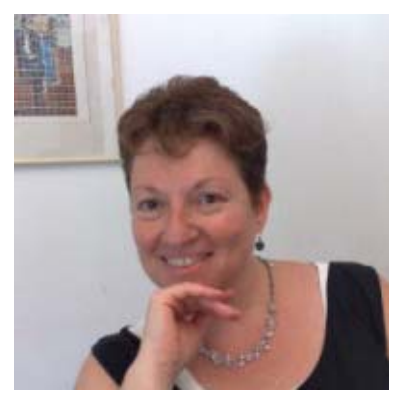

Tami Neuthal is an information specialist and instructional designer in the Center for Information Technology in Distance Education in the Open University of Israel. She also teaches information literacy and social media use in several teachers' professional development programs. Her main interests are knowledge management in academia, social media as personal learning environments, and online collaboration within communities of practice. 